\title{
Constipation in the period of limited isolation during COVID-19 pandemic
}

\author{
Sevcan Alkan Kayaoglu ${ }^{1 *}$ (1), Ozlem Zeliha Sert ${ }^{1}$
}

\section{SUMMARY}

OBJECTIVE: COVID-19 outbreak has become widespread globally and caused a new global chaos. This outbreak that completely affected the lifestyle of individuals resulted in periods of isolation. Here, we evaluated the effects of lifestyle changes with isolation on constipation.

METHODS: A survey on constipation was performed during the 12-week isolation period starting in March 2020 in Turkey. Data of 390 individuals who participated in the survey through the social media and who were actively employed prior to isolation were analyzed. Rome IV criteria were used to evaluate constipation.

RESULTS: Among the participants in the study, 253 (64.9\%) were women with the mean age of $39.5 \pm 9.5$ years. A statistically significant association was found between the decreased water consumption during the isolation period and constipation after the isolation ( $p=0.020 ; p<0.05)$. A significant association was found between the changes in physical activity and constipation after the isolation ( $p=0.013 ; p<0.05$ ). New development of constipation during the isolation or declaration of increased constipation was found to be statistically associated with post-isolation constipation according to Rome criteria ( $p=0.000 ; p<0.05)$.

CONCLUSION: The data of this present study demonstrated that isolation period was effective on the newly developed constipation. Decreased physical activity and water consumption are also effective on constipation.

KEYWORDS: Constipation. Pandemic. COVID.

\section{INTRODUCTION}

A new coronavirus (COVID-19) was reported to infect humans through droplet spread starting from China in December 2019 rapidly to other countries and caused deaths due to respiratory failure. Therefore, World Health Organization (WHO) declared the situation as a pandemic on March $11,2020^{1}$. In addition, many countries implemented various preventive measures and limitations such as social distancing rules and intermittent quarantine in order to prevent or slow down the spread of the virus. Quarantine has been reported to have negative effects such as psychological stress, insomnia, low mode, and post-traumatic stress disorders on individuals as was known in the SARS era². In addition, it was demonstrated that the risk of eating disorders is increased during quarantine, in contrast to adaptation to healthier nutrition ${ }^{3,4}$.

Constipation is a disorder of the gastrointestinal system and is defined as decreased frequency of stools, hard defecation, excess strain, decreased stool passage, or sensation of incomplete evacuation and could be developed due to isolation or underlying disorders 5 . Rome IV diagnostic criteria have been used to evaluate the changes in defecation and Bristol stool scale for the categorization of the shape of the stools ${ }^{6}$.
Incidence of constipation in this country is around 20\%, according to a study performed ${ }^{7}$. Median prevalence in the world is $16 \%$ and constipation is frequently seen in female gender aged above 60 years. Constipation is associated with sedentary lifestyle, nutrition composed of low fibers, drugs, anxiety, depression, and somatization as well as changes in the lifestyle ${ }^{5,6,8,9}$. Also, quality of life of individuals is negatively associated with constipation ${ }^{10}$. Thus, since limiting people to home causes negative changes in eating habits, psychological conditions, and physical activity level, these negative effects might have negative impact on defecation habits as well.

The aim of this cross-sectional and online survey study was to evaluate whether the rate of constipation was changed in this country among the employed individuals during the COVID19-associated isolation period. The first case of COVID-19 in Turkey was declared on March 11, 2020, the day when WHO first declared the pandemic. Schools were closed on March 16, 2020 and education was turned to online style gradually $^{11}$. Cafes and restaurants were closed on March 21, 2020, services were changed to takeaway ${ }^{11}$, and intense precautions were implemented using an application called "stay home." A partial quarantine was declared from March 2020 to May 2020. Many firms started to implement home office working

${ }^{1}$ Haydarpasa Numune Training and Research Hospital, Department of General Surgery - Istanbul, Turkey.

${ }^{*}$ Corresponding author: sevcanalkan82@gmail.com

Conflicts of interest: the authors declare there is no conflicts of interest. Funding: none.

Received on October 08, 2021. Accepted on November 20, 2021. 
order and flexible working hours were implemented for public employees ${ }^{12}$. The total number of cases in this period was 141,475 with 3,894 deaths. As a result, majority of the population stayed home for 12 weeks $^{11}$.

\section{METHODS}

This cross-sectional survey study was designed as online questions and was used to evaluate the changes in the rate of constipation among the employed individuals during the limited quarantine period in the COVID-19 outbreak. It was performed in Turkey, in which Istanbul was the city with the highest number of cases. Although 404 individuals answered the survey questions, the results of 390 individuals were included in the evaluation after exclusion of the remaining responses due to duplicate answers and mismatch with the inclusion criteria. Ethics board approval was obtained from local ethics board committee (number: HNEAH-KAEK 2020/KK/109). Also, the study was conducted in accordance with the ethical standards of Declaration of Helsinki (revised in 2013). The study was conducted through the social media (e.g., WhatsApp and Twitter) preparing Google forms between June and July 2020. Forms filled in by the individuals were transferred to the authors by email. A group of individuals who were 18 years or older, had no chronic drug use interfering with the gastrointestinal (GI) system, and actively employed prior to the quarantine were included in this study. Individuals who were using drugs that cause constipation or who were under the treatment of constipation, who were not actively employed, had immobilization for any reason (e.g., cerebrovascular disease [CVD] and major depression), had GI surgery, and who refused to participate in the study were excluded from the study. A total of 36 questions were present in the survey. The questions were designed by the authors including questions on the demographic data of the group included, groups of occupation, accommodation during the isolation period, changes in the eating habits, physical activity status, sleep and stress conditions, presence of symptoms of constipation before (using Rome IV criteria) ${ }^{13}$ and its duration, if present, changes in defecation habits, stool shapes (using Bristol scale) ${ }^{10}$, and drug use in the newly developed constipation. In contrast, chronically used drugs, prior GI surgery, and comorbidities of the individuals were questioned.

\section{Statistical analysis}

IBM SPSS Statistics 22 (IBM SPSS, Turkey) program was used in the statistical analyses when evaluating the findings of the study. Descriptive statistical methods (mean, standard deviation, and frequency), in addition to chi-square test, Fisher's exact chi-square test, continuity (Yates) correction, and McNemar test, were used in the comparison of qualitative data. A p-value $<0.05$ was considered statistically significant.

\section{RESULTS}

The study was conducted in a total of 390 individuals with an age between 17 and 67 years and with 253 (64.9\%) females and $137(35.1 \%)$ males. Mean age was $39.5 \pm 9.5$ years. A total of $66(16.9 \%)$ participants had a chronic disease. A majority of the employed participants were teachers $(n=118,30.25 \%)$.

According to the data shown in Table 1, the rate of straining in at least one-fourth of the defecations was $29.7 \%$ prior to the isolation, while this rate was found to statistically significantly regress to $22.6 \%$ after the isolation ( $\mathrm{p}=0.001 ; \mathrm{p}<0.05)$. The rate of frequency of defecation less than three times a week was $5.9 \%$ prior to the isolation, while this rate was found to statistically significantly regress to $2.8 \%$ after the isolation $(\mathrm{p}=0.004 ; \mathrm{p}<0.05)$. Rate of rare soft stools without laxative use was $8.5 \%$ prior to the isolation, while this rate was found to statistically significantly regress to $5.6 \%$ after the isolation $(\mathrm{p}=0.019 ; \mathrm{p}<0.05)$. Number of cases with constipation according to Rome criteria prior to the isolation was 59 (15.1\%), while it was $48(12.3 \%)$ after the isolation. No statistically significant difference was observed in the general rate of constipation between the periods before and after isolation ( $p>0.05$ ).

The answer to the question "was there any newly formed constipation or any increase in the pre-existing constipation?" was "yes" in $15.4 \%$. Among 60 individuals who responded "yes," $18.3 \%$ stated that they started to use drugs for this reason or they increased the frequency of drug use.

Questions related with constipation after the isolation are presented in Table 2 . A statistically significant association was found between the decreased water consumption during the isolation period and constipation after the isolation period $(\mathrm{p}=0.020 ; \mathrm{p}<0.05)$. A statistically significant association was found between the changed physical activity during the isolation period and constipation after the isolation period $(\mathrm{p}=0.013$; $\mathrm{p}<0.05)$. The rate of constipation in individuals with a decreased physical activity (15.1\%) was significantly higher compared with the ones with increased activity $(10.2 \%)$ and unchanged activity (1.6\%).

New development of constipation during the isolation or declaration of increased constipation were found to be statistically associated with post-isolation constipation according to Rome criteria $(\mathrm{p}=0.000 ; \mathrm{p}<0.05)$. Among the individuals who 
Table 1. Evaluation of the change in defecation symptoms after isolation compared with before isolation.

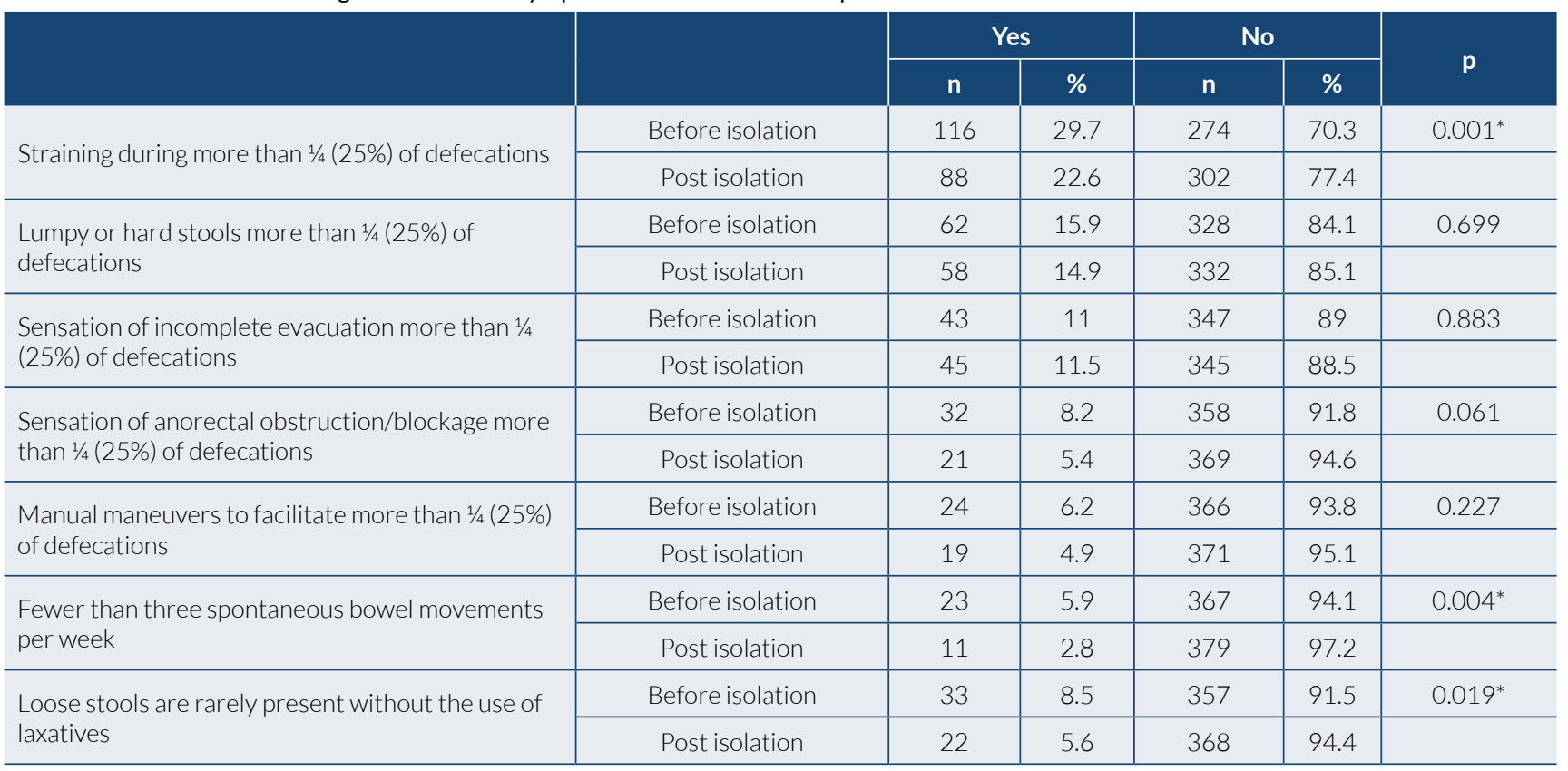

McNemar test. ${ }^{*} p<0.05$.

stated that they had new development of constipation during the isolation or had an increased rate of constipation, $40 \%$ had constipation after the isolation. Among the individuals who declared development of no new constipation, 7.3\% had constipation after the isolation (Table 3).

\section{DISCUSSION}

Functional constipation has been demonstrated to negatively affect the quality of life in many studies ${ }^{14,15}$. The term constipation is perceived differently among the patients and, thus, many individuals who define themselves constipated might actually not accepted as constipated according to the Rome criteria ${ }^{13-16}$.

In a survey including 5,155 individuals, only half of the participants thought that constipation was a health-related problem ${ }^{17}$. Physical activity, improving fluid intake when decreased, and fiber-rich nutrition are known to be effective in preventing constipation ${ }^{14,18}$. No relationship could be established between fiber-rich nutrition and constipation. Yet, fiberrich nutrition is recommended in the treatment of functional constipation ${ }^{19}$. Among the participants in the survey, 74.1\% reported a decreased rate of take-home food, although a partial increase (33.8\%) in the consumption of preprepared food intake was the subject. However, fiber-rich food intake was unchanged clearly in $262(67.2 \%)$ individuals. This suggests that individuals increased cooking home due to the isolation and also fear of catching the disease and they balanced their nutrition in favor of fiber-rich food.

The significant association of Rome criteria confirmed rate of newly developed constipation and isolation demonstrates that isolation period was effective on constipation. Decreased physical activity and water consumption are also effective on constipation. Constipation, especially when it becomes a chronic problem, causes nonignorable costs in the healthcare system and labor loss ${ }^{15}$. Considering possible future isolation due to pandemic, evaluation of some organ system dysfunctions such as constipation during the isolation period and preventive measures against them will allow labor loss of the personnel with a decreased work tempo and the economical costs might be eased. Although many drugs can be prescribed for constipation, many patients take them in a decreased dose or frequency due to side effects or stop using the drugs and many physicians prescribe drugs more than required ${ }^{16}$. The first approach for the treatment of constipation should be changing eating habits and lifestyle ${ }^{20}$. Increasing water intake for constipation that would possibly develop during the isolation period is beneficial for an individual in many ways and is an easy-to-apply method of initial treatment.

Increased stress causes differences in gastrointestinal system habits ${ }^{21}$. Constipation has been associated with stress in some studies; however, the rate of constipation was not significantly increased in the group of individuals who stated an increased stress with isolation in this present study ${ }^{18,22}$. 
Table 2. Evaluations of post-isolation constipation.

\begin{tabular}{|c|c|c|c|c|}
\hline & & \multicolumn{2}{|c|}{ Post isolation constipation according to Rome 4 Criteria } & \multirow{3}{*}{ p } \\
\hline & & Yes & No & \\
\hline & & $n(\%)$ & $\mathrm{n}(\%)$ & \\
\hline \multirow{2}{*}{$\begin{array}{l}\text { Accommodation elsewhere during the } \\
\text { isolation period }\end{array}$} & Yes & $6(9.4)$ & $58(90.6)$ & $0.567^{\mathrm{a}}$ \\
\hline & No & $42(12.9)$ & $284(87.1)$ & \\
\hline \multirow{2}{*}{ Accommodation $(n=64)$} & House & $5(14.3)$ & $30(85.7)$ & $0.209^{b}$ \\
\hline & Others & $1(3.4)$ & $28(96.6)$ & \\
\hline \multirow{3}{*}{$\begin{array}{l}\text { Number of meals during the isolation } \\
\text { period }\end{array}$} & Increased & $19(15.3)$ & $105(84.7)$ & $0.455^{c}$ \\
\hline & Decreased & $7(11.7)$ & $53(88.3)$ & \\
\hline & Unchanged & $22(10.7)$ & $184(89.3)$ & \\
\hline \multirow{3}{*}{$\begin{array}{l}\text { The amount of food ordered from } \\
\text { outside during the isolation period }\end{array}$} & Increased & $1(5.9)$ & $16(94.1)$ & $0.695^{c}$ \\
\hline & Decreased & $37(12.8)$ & $252(87.2)$ & \\
\hline & Unchanged & $10(11.9)$ & $74(88.1)$ & \\
\hline \multirow{3}{*}{$\begin{array}{l}\text { Food consumption during the isolation } \\
\text { period }\end{array}$} & Increased & $24(13)$ & $160(87)$ & $0.901^{c}$ \\
\hline & Decreased & 5 (10.9) & 41 (89.1) & \\
\hline & Unchanged & 19 (11.9) & 141 (88.1) & \\
\hline \multirow{3}{*}{$\begin{array}{l}\text { Packaged product consumption during } \\
\text { the isolation period }\end{array}$} & Increased & $19(14.4)$ & $113(85.6)$ & $0.477^{c}$ \\
\hline & Decreased & $10(9.3)$ & $98(90.7)$ & \\
\hline & Unchanged & $19(12.7)$ & 131 (87.3) & \\
\hline \multirow{3}{*}{$\begin{array}{l}\text { Water consumption during the isolation } \\
\text { period }\end{array}$} & Increased & $28(13.8)$ & $175(86.2)$ & $0.020^{c *}$ \\
\hline & Decreased & $6(28.6)$ & $15(71.4)$ & \\
\hline & Unchanged & $14(8.4)$ & $152(91.6)$ & \\
\hline \multirow{3}{*}{$\begin{array}{l}\text { Physical activity status during the } \\
\text { isolation period }\end{array}$} & Increased & $5(10.2)$ & $44(89.8)$ & $0.013^{c *}$ \\
\hline & Decreased & $42(15.1)$ & 237 (84.9) & \\
\hline & Unchanged & $1(1.6)$ & $61(98.4)$ & \\
\hline \multirow{3}{*}{$\begin{array}{l}\text { Consumption of fibrous food during the } \\
\text { isolation period }\end{array}$} & Increased & $12(13.2)$ & 79 (86.8) & $0.159 c$ \\
\hline & Decreased & $8(21.6)$ & $29(78.4)$ & \\
\hline & Unchanged & $28(10.7)$ & 234 (89.3) & \\
\hline \multirow{3}{*}{$\begin{array}{l}\text { Daily sleep time during the isolation } \\
\text { period }\end{array}$} & Increased & $26(14.8)$ & $150(85.2)$ & $0.221^{c}$ \\
\hline & Decreased & $9(14.1)$ & 55 (85.9) & \\
\hline & Unchanged & $13(8.7)$ & $137(91.3)$ & \\
\hline \multirow{3}{*}{$\begin{array}{l}\text { Stress situation felt during the isolation } \\
\text { period }\end{array}$} & Increased & 37 (13.3) & $242(86.7)$ & $0.290^{c}$ \\
\hline & Decreased & 1 (3.3) & $29(96.7)$ & \\
\hline & Unchanged & $10(12.3)$ & $71(87.7)$ & \\
\hline
\end{tabular}

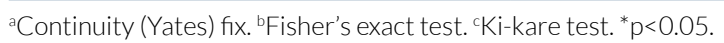

Table 3. Evaluation of the relationship between the increase in new constipation caused by isolation and post-isolation constipation according to the Rome criteria.

\begin{tabular}{l|c|c|c|}
\multirow{2}{*}{} & & \multicolumn{2}{|c|}{ Constipation after isolation according to the Rome criteria } \\
\cline { 2 - 4 } & & Yes & No \\
\cline { 2 - 4 } & & $\mathbf{n}(\%)$ & $365(60)$ \\
\hline $\begin{array}{l}\text { New constipation or increased constipation } \\
\text { associated with isolation }\end{array}$ & Yes & $24(40)$ & $306(92.7)$ \\
\cline { 2 - 4 }
\end{tabular}

Ki-kare test. ${ }^{*} p<0.05$. 
The effects of acute and chronic stress on intestinal function may vary. Stress causes an increase in the contraction activity of the intestines. Chronic stress has been associated with inflammatory bowel disease and irritable bowel disease. Stress might result in constipation or diarrhea. The isolation period evaluated was a process of 3 months, and analysis of the effect of chronic stress in isolation in longer periods might have different results $\mathrm{s}^{23}$. Evaluation of the association of constipation and chronic stress might be beneficial since constipation is known to have a psychological component ${ }^{14}$.

Many constipated patients who deny to present to the health care facilities and who refuse to share their personal information might participate in the surveys safely. Especially, the employed fraction of the society reach Internet easily and use it actively. Thus, the group reached through the Internet in order to obtain data on the problem of constipation has the qualification to reflect the employed fraction of the society ${ }^{17}$.

This study may not reflect the whole society since only the group of employed people were included in the survey. Low socioeconomic status and low level of education are risk factors for constipation ${ }^{24}$. The nutritional habits and thus rates

\section{REFERENCES}

1. Sidor A, Rzymski P. Dietary choices and habits during COVID-19 lockdown: experience from Poland. Nutrients. 2020;12(6):1657. https://doi.org/10.3390/nu12061657

2. Brooks SK, Webster RK, Smith LE, Woodland L, Wessely S, Greenberg N, et al. The psychological impact of quarantine and how to reduce it: rapid review of the evidence. Lancet (London, England). 2020;395(10227):912-20. https://doi.org/10.1016/ S0140-6736(20)30460-8

3. Rodríguez-Pérez C, Molina-Montes E, Verardo V, Artacho R, García-Villanova B, Guerra-Hernández EJ, et al. Changes in dietary behaviours during the COVID-19 outbreak confinement in the Spanish COVIDiet study. Nutrients. 2020;12(6):1730. https:// doi.org/10.3390/nu12061730

4. Rodgers RF, Lombardo C, Cerolini S, Franko DL, Omori M, Fuller-Tyszkiewicz M, et al. The impact of the COVID-19 pandemic on eating disorder risk and symptoms. Int J Eat Disord. 2020;53(7):1166-70. https://doi.org/10.1002/eat.23318

5. Bharucha AE, Pemberton JH, Locke GR. American Gastroenterological Association technical review on constipation. Gastroenterology. 2013;144(1):218-38. https://doi.org/10.1053/j. gastro.2012.10.028

6. RaoSSC, RattanakovitK, PatcharatrakulT.Diagnosisand management of chronic constipation in adults. Nat Rev Gastroenterol Hepatol. 2016;13(5):295-305. https://doi.org/10.1038/nrgastro.2016.53

7. Uz B, Türkay C, Bavbek N, IS Ik A, Erbayrak M, Uyar M. Evaluation of patients with constipation. Akademik Gastroenteroloji Dergisi. 2006:5(1):56-9.

8. AlhossanA,AlrabiahZ,Alghadeer SM,WajidS,Al-ArifiMN,Babelghaith $\mathrm{SD}$. Satisfaction levels concerning current chronic constipation of constipation may not reflect the whole society since the participants in the survey had a definite level of income and level of education. However, we suggest that the group of participants in the survey reflected the employed part of the society as well, since the aim of this study was to evaluate the rate of constipation in the employed fraction of the society with isolation.

\section{CONCLUSIONS}

The rate of newly developed constipation is increasing in the isolation period. Increasing physical activity and water intake might solve the problem as a first step in order to improve the quality of life and increase work productivity in the future possible isolation condition.

\section{AUTHORS' CONTRIBUTIONS}

SAK, OZS: Conceptualization, Formal Analysis, Funding acquisition, Investigation, Methodology, Project administration, Resources, Software, Supervision.

treatment options in Saudi Arabia. Gastroenterol Res Pract. 2020;2020:6545121. https://doi.org/10.1155/2020/6545121

9. Forootan M, Bagheri N, Darvishi M. Chronic constipation: a review of literature. Medicine. 2018;97(20):e10631. https://doi. org/10.1097/MD.0000000000010631

10. Maruyama M, Kamimura K, Sugita M, Nakajima N, Takahaski Y, Isokawa $\mathrm{O}$, et al. The management of constipation: current status and future prospects. In: Mózsik G, editor. Constipation. 9th ed. IntechOpen; 2019. https://doi.org/10.5772/intechopen.83467.

11. Budak F, Korkmaz S. An overall evaluation for the Covid-19 pandemic process: the case of Turkey. Sosyal Aras tırmalar ve Yönetim Dergisi. 2020;1(1):62-79.

12. Turan A, Çelikyay HH. Türkiyéde KOVID-19ile Mücadele: Politikalar ve Aktörler. Uluslararası Yönetim Akademisi Dergisi. 2020;3(1):1 25. https://doi.org/10.33712/mana.733482

13. Drossman DA. Functional gastrointestinal disorders: history, pathophysiology, clinical features, and Rome IV. Gastroenterology.2016;150(6):1262-79. https://doi.org/10.1053/j. gastro.2016.02.032

14. Wald A, Scarpignato C, Kamm MA, Mueller-Lissner S, Helfrich I, Schuijt $C$, et al. The burden of constipation on quality of life: results of a multinational survey. Aliment Pharmacol Ther. 2007;26(2):22736. https://doi.org/10.1111/j.1365-2036.2007.03376.x

15. Sun SX, Dibonaventura M, Purayidathil FW, Wagner JS, Dabbous O, Mody R. Impact of chronic constipation on health-related quality of life, work productivity, and healthcare resource use: an analysis of the National Health and Wellness Survey. Dig Dis Sci. 2011;56(9),2688-95. https://doi.org/10.1007/s10620-011 $1639-5$

16. Ohkubo H, Yoshihara T, Misawa N, Ashikari K, Fuyuki A, Matsuura T, etal. Relationship betweenstool formand quality of life in patients with 
chronic constipation: an Internet Questionnaire Survey. Digestion. 2021;102(2):147-54. https://doi.org/10.1159/000502815

17. Tamura A, Tomita T, Oshima T, Toyoshima F, Yamasaki T, Okugawa T, et al. Prevalence and self-recognition of chronic constipation: results of an Internet Survey. J Neurogastroenterol Motil. 2016;22(4):67785. https://doi.org/10.5056/jnm15187

18. Mearin F, Lacy BE, Chang L, Chey WD, Lembo AJ, Simren M, et al. Bowel disorders. Gastroenterology. 2016;S00165085(16)00222-5.https://doi.org/10.1053/j.gastro.2016.02.031

19. Gill SK, Rossi M, Bajka B, Whelan K. Dietary fibre in gastrointestinal health and disease. Nat Rev Gastroenterol Hepatol. 2021;18(2):10116. https://doi.org/10.1038/s41575-020-00375-4

20. Lucak S, Lunsford TN, Harris LA. Evaluation and treatment of constipation in the geriatric population. Clin Geriatr Med. 2021;37(1):85-102. https://doi.org/10.1016/j.cger.2020.08.007
21. Balmus IM, Robea M, Ciobica A, Timofte D. Perceived stress and gastrointestinal habits in college students. Acta Endocrinol (Buchar). 2019;15(2):274-5. https://doi.org/10.4183/aeb.2019.274

22. Yildirim MA, Cakir M, Bicer M, Senturk M, Yonar H, Gur MN, et al. Lifestyle and chronic constipation in medical students. Gastroenterol Res Pract. 2021;2021:4752614. https://doi. org/10.1155/2021/4752614

23. Bhatia $\mathrm{V}$, Tandon RK. Stress and the gastrointestinal tract. J Gastroenterol Hepatol. 2005;20(3):332-9.https://doi.org/10.1111/ j.1440-1746.2004.03508.x

24. Snell DB, Faruqui S, Bosworth BP. A case-based approach to constipation in primary care. Med Clin North Am. 2021;105(1):5573. https://doi.org/10.1016/j.mcna.2020.08.015 